\title{
Research on D Section Steel Tube Filled with Concrete Used for High Stress Roadway Support in Deep Mines
}

\author{
Qinghai Li \\ College of Mining and Safety \\ Engineering \\ Shandong University of Science and \\ Technology \\ Qingdao, China \\ liqinghai@sdust.edu.cn \\ Zhen Li \\ College of Mining and Safety \\ Engineering \\ Shandong University of Science and \\ Technology \\ Qingdao, China \\ 767312022@qq.com
}

\author{
Limin Liu \\ College of Mining and Safety \\ Engineering \\ Shandong University of Science and \\ Technology \\ Qingdao, China \\ lmliuhhu@163.com
}

\author{
Jingkai Li \\ College of Mining and Safety \\ Engineering \\ Shandong University of Science and \\ Technology \\ Qingdao, China \\ LJk_0801@163.com
}

\begin{abstract}
In view of large deformation of return air roadway in No. 10 coal mine, this paper puts forward a new support of $D$ section steel tube filled with concrete. In this paper, method of numerical simulation has been used to analyze the effect of this support. Based on compression simulation of circular ring, according to fractal geometry, the section of steel tube is designed as D section. By comparison, it is determined that the compressive strength of $D$ section short steel tube filled with concrete is greater than that of circular section one and square section one. When lateral pressure coefficients are 1.0 and 1.5, the stress state in $D$ section support is better than that of circular section support. By simulation, it is demonstrated that $D$ section support is effective in roadway supporting. Through field application, it is verified that $D$ section support is effective in high stress roadway supporting in deep mines.
\end{abstract}

Keywords-D section steel tube filled with concrete, high stress roadway, deep mines, numerical simulation, field application

\section{INTRODUCTION}

Coal is an important resource in the development of national economy. With the increase of coal production, shallow coal resources could not meet the needs and the mining process extends to the deep. With the increase of mining depth, there has encountered the problem of high stress soft rock supporting in deep mines, which has brought serious impact on field production. More than $70 \%$ of coal reserves are buried deeper than $800 \mathrm{~m}$ in China. Thus, most mining areas are and will be faced deep mining problems now or in the future. For high stress roadway support in deep mines, experts have proposed some control measures in terms of active support, passive support, et al. In terms of active supports, $\mathrm{He}$ [1] and Sun [2] proposed the theory of coupled support for soft rock roadway and developed a constant-resistance large-deformation anchor (cable). Kang [3] proposed the theory of high prestress and high strength support, and developed high strength bolts (cables). Zhang [4] proposed three high (high strength, high pretension, high stiffness) bolting support technology. In the field of passive supports, Gao [5] and $\mathrm{Li}$ [6] developed circular and square steel tube filled with concrete support. In terms of supporting components, $\mathrm{Li}$ [7] developed high stress bearing system. In terms of modification of surrounding rocks, Xie [8] and Wang [9] proposed grouting reinforcement technology for cracked surrounding rocks. In terms of strength compensation, Xie [10] proposed reinforcement measures for the deformation of $U$ section steel support in deep mines.

It can be seen that in deep mines, high stress roadway are mainly supported by high strength bolting wire mesh and steel sets [11-17]. In some particularly complex mining areas, the use of bolting wire mesh and steel sets cannot control roadway large deformation. In view of this, based on large deformation of No. 10 coal mine in Pingdingshan Tian'an Coal Industry Co., Ltd, this paper researches and develops high strength supports used for roadway supporting in deep mines. In No. 10 coal mine, the horizontal stress of -320 mining level is violent. In return air roadway in -320 mining level, the shotcrete cracked and the roadway floor heaved up seriously. The return air roadway needs to be repaired one or two times each year. In order to solve this problem, this paper puts forward a new support of D section steel tube filled with concrete. In this paper, method of numerical simulation has been used to analyze the effect of D section steel tube filled with concrete. Through field application, it is verified that $\mathrm{D}$ section steel tube filled with concrete is effective for high stress roadway supporting in deep mines.

\section{DESIGN OF STEEL TUBE SECTION}

Referring to literatures [18-20], it is determined that 
the circular section steel tube filled with concrete exhibit high strength. To optimize the section of steel tube, under compression, force state of circular section was analyzed by simulation. The circular section is simplified as ring. ANSYS software is used in simulation. The ring model is shown in Fig. 1. To observe the deformation of the ring, the lower surface of the ring is fixed and the upper surface is loaded by $2000 \mathrm{~N}$ loads. Parameters are shown in Table 1 .

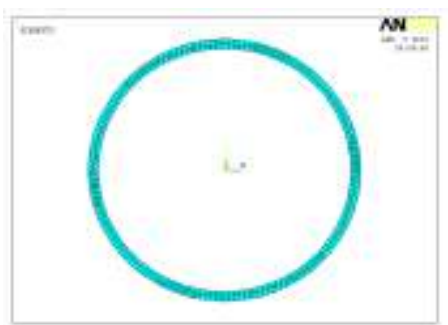

Fig.1. Model of circular section steel tube

TABLE1. PARAMETERS OF STEEL TUBE

\begin{tabular}{|c|c|c|c|c|c|}
\hline Material & $\begin{array}{c}\text { Poisson } \\
\text { Ratio }\end{array}$ & $\begin{array}{c}\text { Elastic } \\
\text { Modulus } \\
\text { / N•mm }\end{array}$ & $\begin{array}{c}\text { Plastic } \\
\text { modulus } \\
/ \mathrm{N} \cdot \mathbf{m m}^{-2}\end{array}$ & $\begin{array}{c}\text { Yield } \\
\text { stress } \\
\text { / N•mm } \\
\end{array}$ & $\begin{array}{l}\text { Density } \\
/ \text { g•cm }\end{array}$ \\
\hline $\begin{array}{c}\text { Q235 } \\
\text { steel pipe }\end{array}$ & 0.280 & $2.06 \times 105$ & $0.15 \times 105$ & 300 & 7.85 \\
\hline
\end{tabular}

After simulation, the ring's section is gained and shown in Fig. 2, and the ring's displacement is gained and shown in Fig. 3. After simulation, the ring deformed largely and was close to the letter D. Based on this conclusion, according to fractal geometry, the section of steel tube is designed as D section, and its size is shown in Fig. 4.

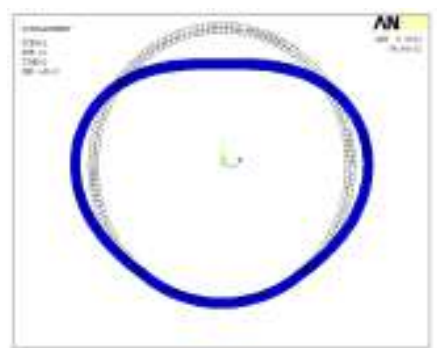

Fig.2. Shape of circular section after loading

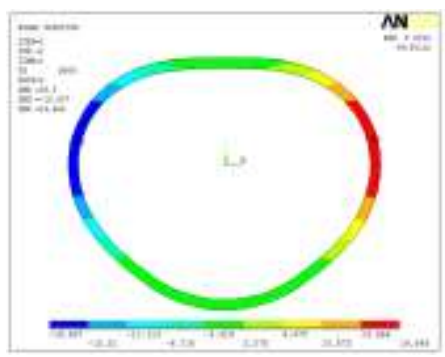

(a) $\mathrm{X}$ direction

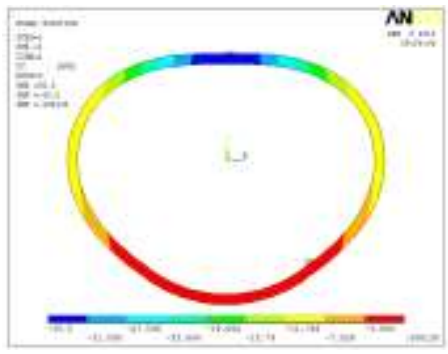

(b) $\mathrm{Y}$ direction

Fig.3. Displacement cloud maps of circular section steel tube

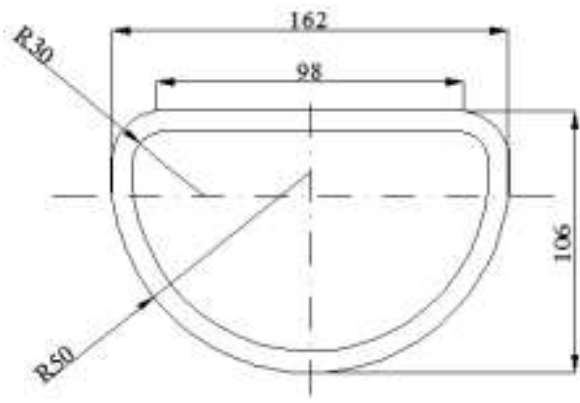

Fig.4. Size of D section steel tube (unit: $\mathrm{mm}$ )

\section{COMPRESSIVE STRENGTH OF SHORT STEEL TUBE FILLED WITH CONCRETE}

In order to compare the compressive strength of short steel tubes filled with concrete, axial force analysis on circular section, D section and square section steel tube filled with concrete are conducted by ANSYS simulation. The diameter of circular section is $140 \mathrm{~mm}$. According to the principle of equal circumference, the size of D section is determined. Similarly, the side length of square section is determined as $110 \mathrm{~mm}$. Due to short steel tubes always with aspect ratio less than $4: 1$, thus the length of short steel tubes is determined as $500 \mathrm{~mm}$.

In simulation, one end of short steel tube is fixed and the other end is loaded. The steel tube is filled with C60 concrete. The parameters of concrete are shown in Table 2. After simulation, displacements of short steel tubes are shown in Fig. 5, Fig. 6 and Fig. 7. It can be seen that the displacement of short circular section steel tube is 0.358 $\mathrm{mm}$ and that of D section steel tube is $0.301 \mathrm{~mm}$. The displacement of square section steel tube is $0.427 \mathrm{~mm}$. As deformation is a response to strength. Therefore, it can be seen that the compressive strength of D section steel tube filled with concrete is greater than that of circular section one. The compressive strength of circular section steel tube filled with concrete is higher than that of square section one.

TABLE2. PARAMETERS OF CONCRETE

\begin{tabular}{|c|c|c|c|c|c|}
\hline Material & $\begin{array}{c}\text { Poisson } \\
\text { Ratio }\end{array}$ & $\begin{array}{c}\text { Elastic } \\
\text { Modulus } \\
\text { / N•mm } \\
\end{array}$ & $\begin{array}{c}\text { Cohesive } \\
\text { force } \\
\text { / N•mm }\end{array}$ & $\begin{array}{c}\text { Friction } \\
\text { angle } \\
/\left(^{\circ}\right)\end{array}$ & $\begin{array}{c}\text { Expansion } \\
\text { angle } \\
/\left(^{\circ}\right)\end{array}$ \\
\hline $\begin{array}{c}\text { C60 } \\
\text { Concrete }\end{array}$ & 0.2 & $3.65 \times 104$ & 5.5654 & $55.6^{\circ}$ & $30^{\circ}$ \\
\hline
\end{tabular}

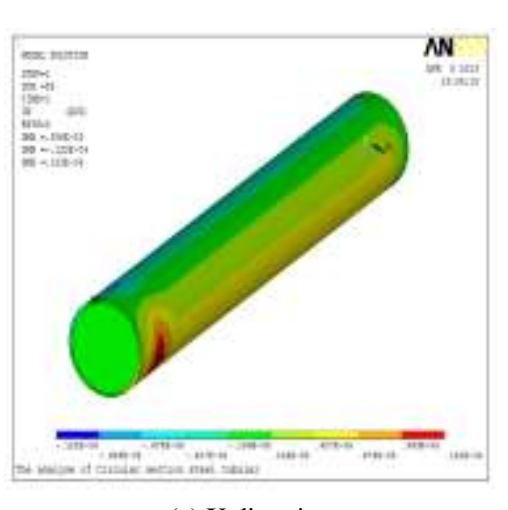

(a) $\mathrm{X}$ direction 


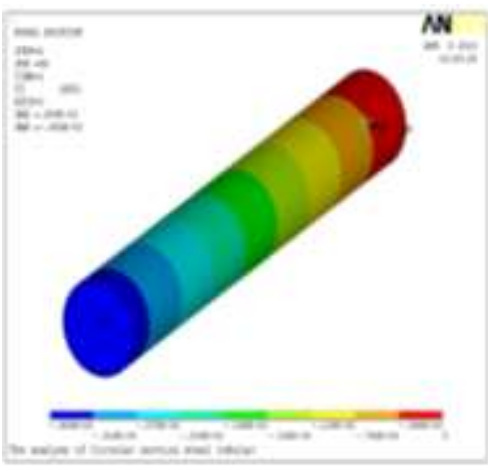

(b) Y direction

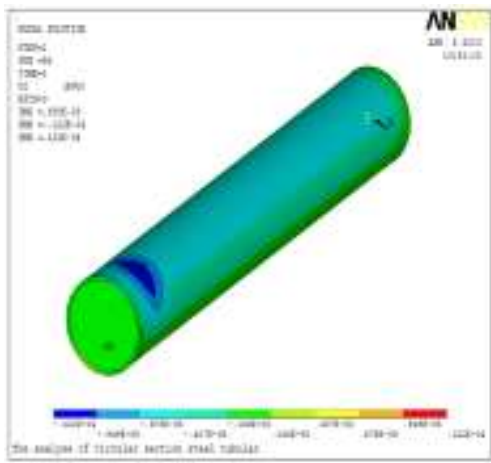

(c) $\mathrm{Z}$ direction

Fig.5. Displacement cloud maps of circular section support

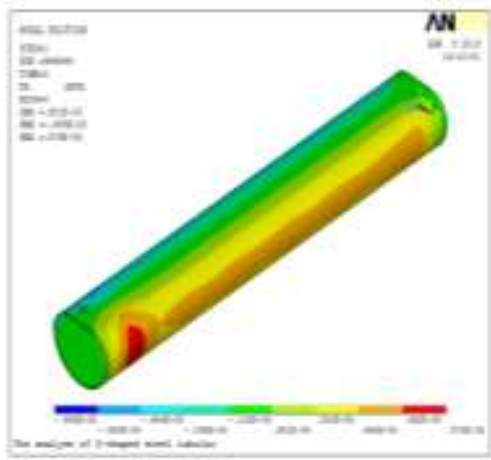

(a) $\mathrm{X}$ direction

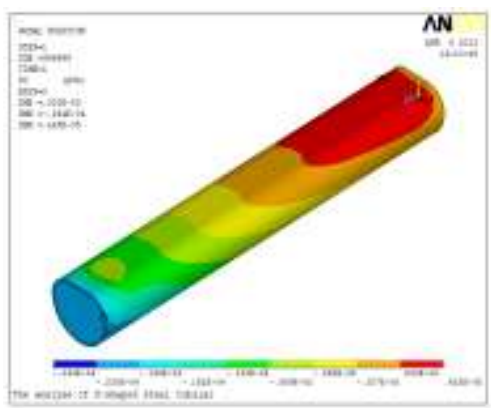

(b) Y direction

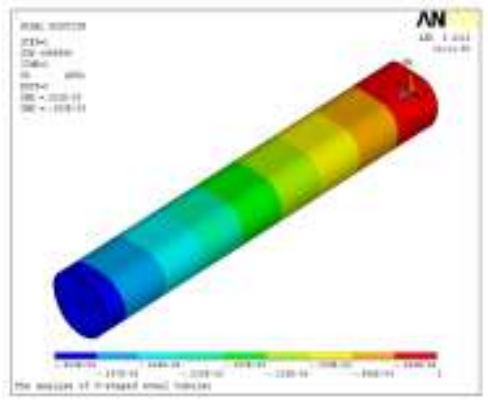

(c) $\mathrm{Z}$ direction

Fig.6. Displacement cloud maps of D section support

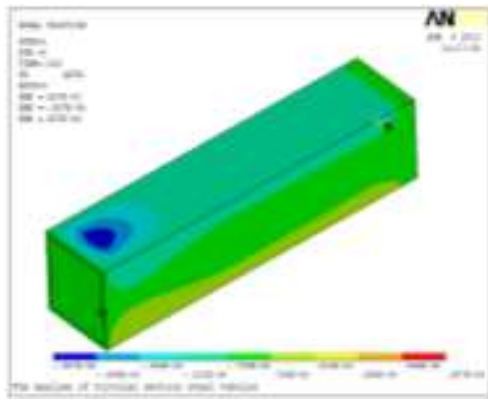

(a) $\mathrm{X}$ direction

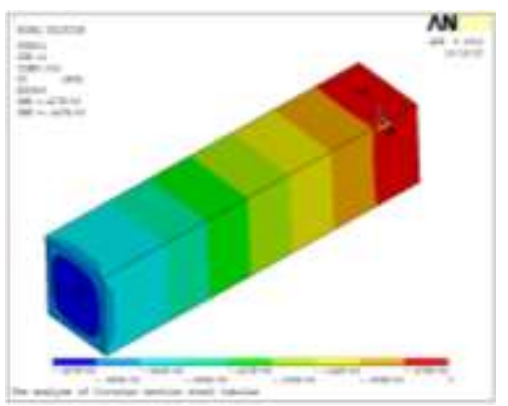

(b) Y direction

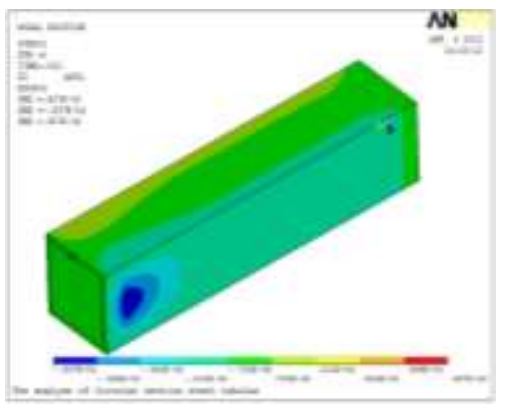

(c) $\mathrm{Z}$ direction

Fig.7. Displacement cloud maps of square section support

IV. ANALYSIS ON STRENGTH OF D SECTION AND CIRCULAR SECTION STEEL TUBE FILLED WITH CONCRETE SUPPORT

\section{A. Strength analysis under lateral pressure coefficient 1.0}

Roadway in horseshoe type is often used in coal mine. The steel tube filled with concrete is made into horseshoe type supports. Stress comparison between D section and circular section supports are conducted by ANSYS simulation. The unenclosed horseshoe type support is shown in Fig. 8. During loading process, the bottom of support was fixed. The top arch and both sides of support were loaded by same loads. The mining depth of No. 10 coal mine is about $600 \mathrm{~m}$. According to field geological conditions, the vertical stress is estimated to be $15 \mathrm{MPa}$. The lateral pressure coefficient is selected to be 1 to analyze. Thus, $15 \mathrm{MPa}$ surface forces is applied to the top arch and both sides of the support at the same time.

As shown in Fig. 9 and Fig. 10, in simulation, the maximum displacement of top arch in D section support is $4.596 \mathrm{~mm}$, and the maximum displacement of top arch in circular section support is $94.863 \mathrm{~mm}$. Under lateral pressure coefficient 1 , the displacement of $\mathrm{D}$ section support is much smaller than that of circular section 
support. Thus the bearing capacity of D section support is much higher than that of circular section support.

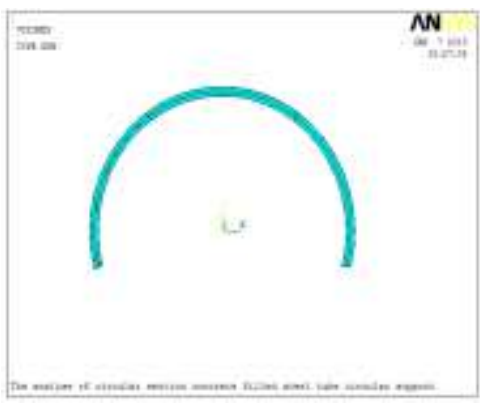

Fig.8. Unenclosed horseshoe type support

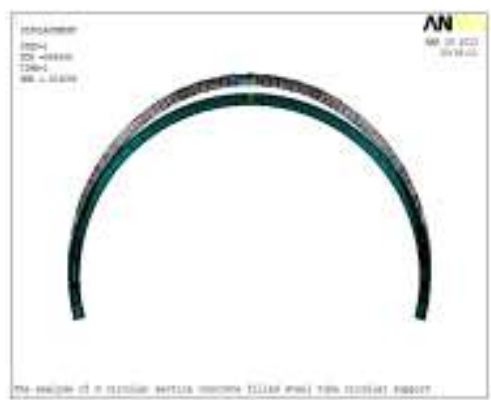

(a) Map of deformation comparison

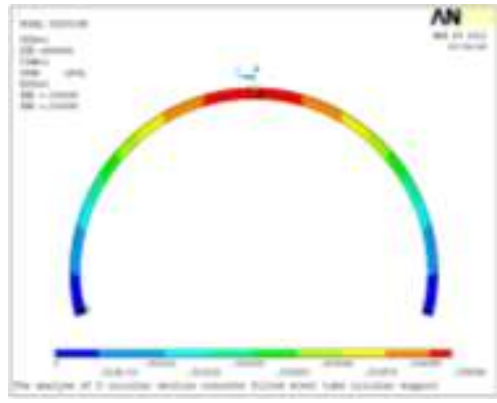

(b) Displacement cloud map

Fig.9. Results of D section support with lateral pressure coefficient 1

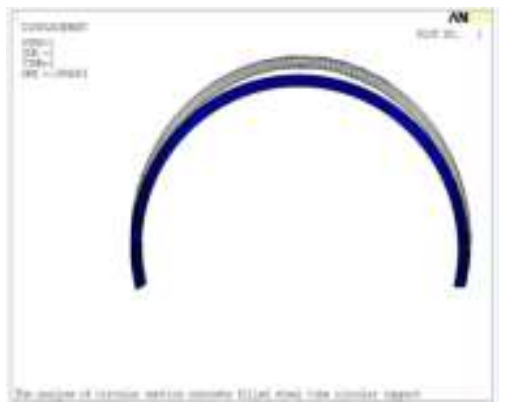

(a) Map of deformation comparison

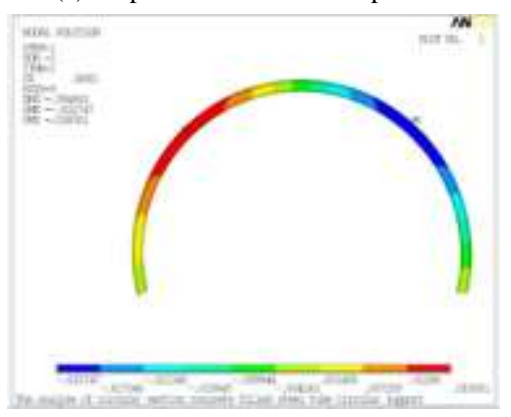

(b) Displacement cloud map

Fig.10. Results of circular section support with lateral pressure coefficient 1

\section{B. Strength analysis under lateral pressure coefficient 1.5}

According to the above analysis, it is determined that the mechanical performance of the $\mathrm{D}$ section steel tube filled with concrete support is better than that of the circular section one. However, because of the distribution of ground stress, the horizontal stress in deep is often higher than that of vertical stress. In this section, the mechanical behavior of the support under lateral pressure coefficient 1.5 to be analyzed in this part. For convenience of loading, circular section and D section supports are divided into three sections with equal arc length, and the corresponding loads are applied to these three segments respectively. According to field condition, $15 \mathrm{MPa}$ surface force is applied to the top arch of the support and 22.5 Mpa surface forces is applied to two sides of the arch. Diagram of horizontal and vertical loads is shown in Fig. 11.

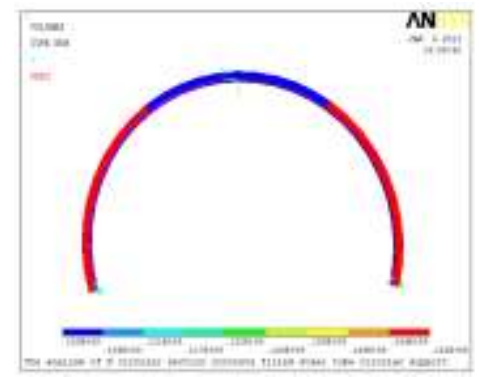

Fig.11. Diagram of horizontal and vertical loads

The displacement and deformation of circular section and D section supports are shown in Fig. 12 and Fig.13. The displacement of top arch in D section support is $718.779 \mathrm{~mm}$, which is far less than that of circular section support $(1185.99 \mathrm{~mm})$. In this situation, the stress state in D section support is better than that of circular section support. That is to say, D section support is more suitable than circular section support in high stress roadway supporting in deep mines.

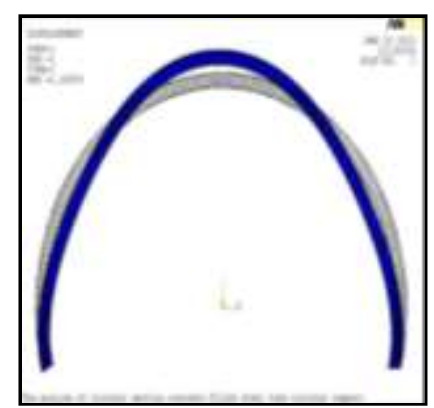

(a) Map of deformation comparison

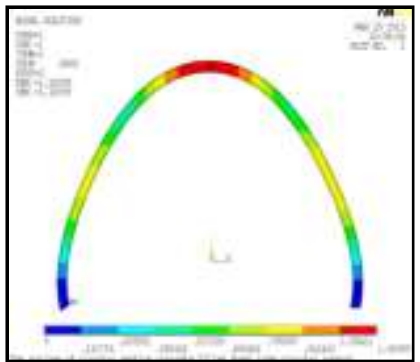

(b) Displacement cloud map

Fig.12. Results of circular section support with lateral pressure coefficient 1.5 


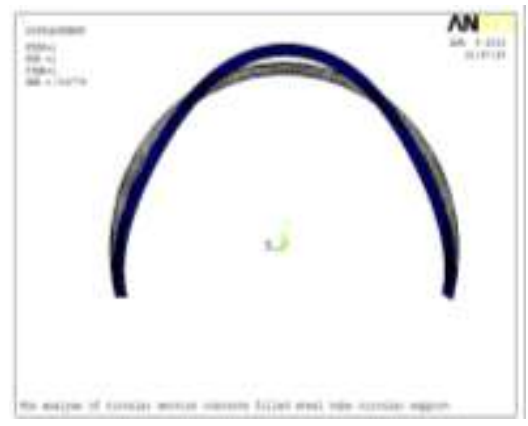

(a) Map of deformation comparison

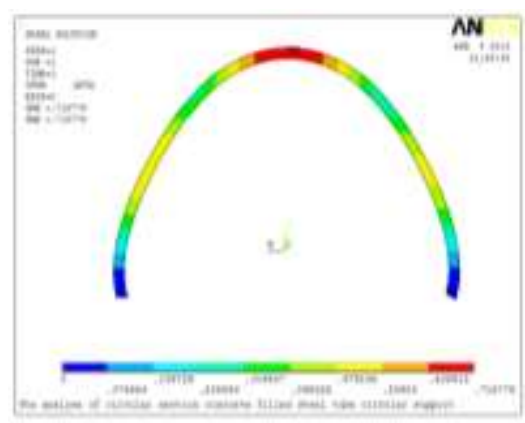

(b) Displacement cloud map

Fig.13. Results of D section support with lateral pressure coefficient 1.5

\section{ANALYSIS ON SUPPORTING RESULTS OF D SECTION STEEL TUBE FILLED WITH CONCRETE SUPPORT}

\section{A. The establishment of model}

In order to analyze the stress of D section steel tube filled with concrete support in strata, surrounding rock with size of $5000 \mathrm{~mm} \times 5000 \mathrm{~mm} \times 500 \mathrm{~mm}$ is set up around the support. The model is shown in Fig. 14. Parameters of surrounding rock are shown in Table 3. The parameters of $\mathrm{D}$ section are the same as above. As the model is relatively small, there is little difference between vertical pressure and horizontal pressure. In loading process, bottom, back and front surfaces of the model are fixed. $15 \mathrm{MPa}$ loads are applied on the top, left and right surfaces of the model.

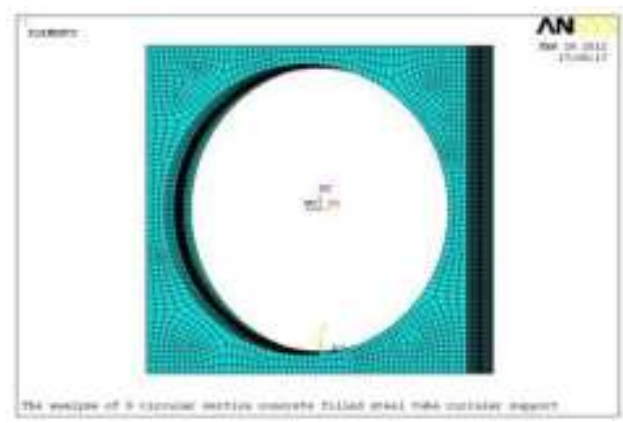

Fig.14. Model of support and surrounding rock

TABLE3. PARAMETERS OF SURROUNDING ROCK

\begin{tabular}{|c|c|c|c|}
\hline Lithology & $\begin{array}{c}\text { Bulk density } \\
/ \mathbf{k g} \cdot \mathbf{m}^{-3}\end{array}$ & $\begin{array}{c}\text { Bulk modulus } \\
/ \mathbf{G P a}\end{array}$ & $\begin{array}{c}\text { Shear modulus } \\
/ \mathbf{G P a}\end{array}$ \\
\hline Strata & 2620 & 11.856 & 9.201 \\
\hline Lithology & $\begin{array}{c}\text { Cohesion } \\
/ \mathbf{M P a}\end{array}$ & $\begin{array}{c}\text { Internal friction } \\
\text { angle/ }\end{array}$ & $\begin{array}{c}\text { Tensile strength } \\
\text { /MPa }\end{array}$ \\
\hline Strata & 2.83 & 39 & 6.91 \\
\hline
\end{tabular}

\section{B. Analysis on simulation results}

The deformation of support and surrounding rock are shown in Fig. 15. Due to concentrated loads, the model deformed obviously at the adjacent area of loading points, but the deformation of D section support is not obviously. Combined with the equivalent stress cloud (Fig. 16), it can be seen that the support controlled surrounding rock effectively. The whole support presents maximum stress state. While on the outside of the support, stress in surrounding rock decreases gradually as distance to support increasing. According to simulation results of displacement and stress, we can see that D section support is effective in roadway supporting. In order to verify the effectiveness of this support further, field test is conducted in the next part.

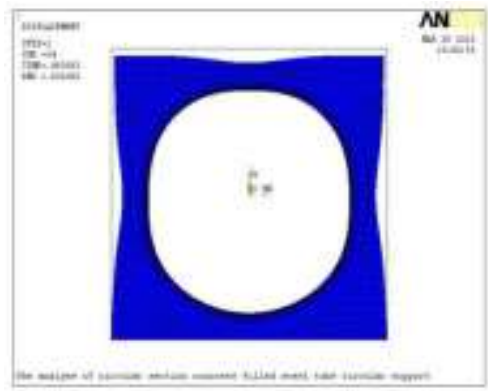

Fig.15. Deformation of support and surrounding rock

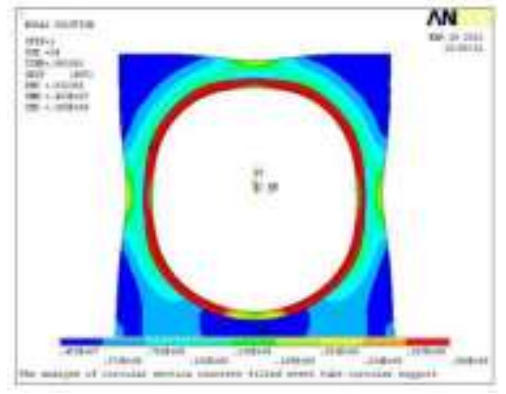

Fig.16. Stress cloud map of support and surrounding rock

\section{FIELD APPLICATION ANALYSIS OF D-SHAPED STEEL CONCRETE STENT}

\section{A. Background of test roadway}

In No. 10 coal mine, the horizontal stress of -320 mining level is violent. In return air roadway in -320 mining level, the shotcrete cracked and the roadway floor heaved up seriously. A variety of supporting methods have been adopted on the site, but almost all failed. In the last repairing, in order to compare the effect of $\mathrm{D}$ section support, two $150 \mathrm{~m}$ roadways supported by $\mathrm{D}$ section steel tube filled with concrete supports and $36 \mathrm{U}$ section steel supports were carried out respectively. The position of test roadway is shown in Fig. 17.

In the first section of test roadway, D section steel tube filled with concrete supports is adopted. Support is in horseshoe type. Supports are made of Q 235 steel with tube type of $\Phi 140 \times 5 \mathrm{~mm}$, and filled with C 60 high strength concrete. Supports space is $700 \mathrm{~mm}$. The design of support is shown in Fig. 18(a). In the second section of the test roadway, $36 \mathrm{U}$ section steel supports are used. Supports space is $700 \mathrm{~mm}$. The design of support is 
shown in Fig. 18(b).

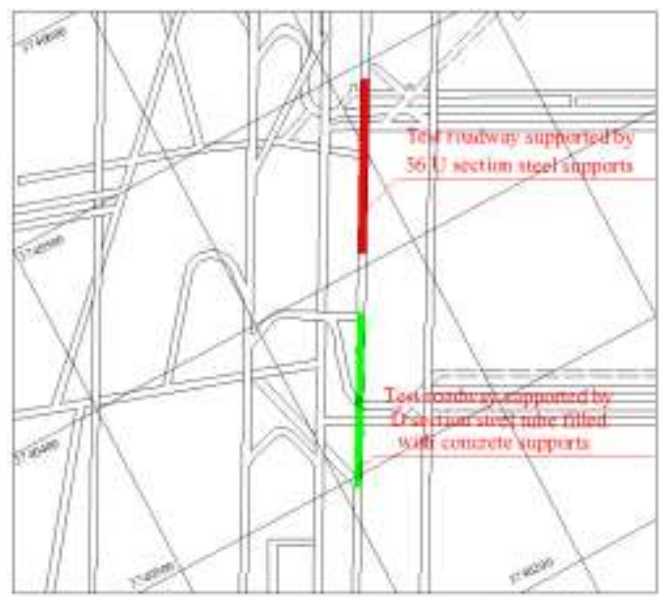

Fig.17. Position of test roadway

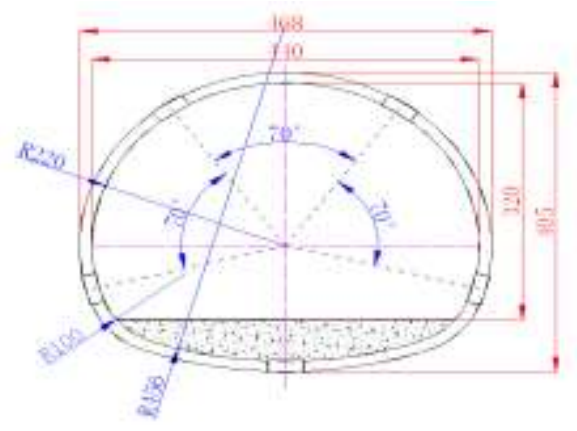

(a) D section steel tube filled with concrete support

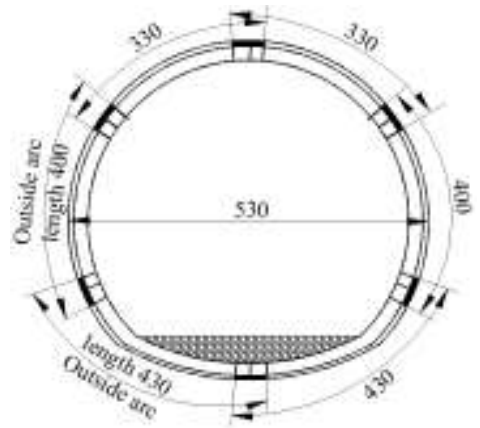

(b) $36 \mathrm{U}$ section steel support

Fig.18. The design of supports (unit: $\mathrm{cm}$ )

\section{B. Analysis on test results}

Rock pressure observation was carried out by setting monitoring points in two test roadways. In view of the displacement around the roadway is the form of surrounding rock movement. And the displacement is one of the most important data to judge the stability of surrounding rock. Then the distance between roof and floor and the distance between two sides are the parameters in field monitoring. In test roadway, groups of monitoring points are set up in every $50 \mathrm{~m}$. After a period of time, test roadway supported by $36 \mathrm{U}$ section steel supports deformed largely. The surrounding rock in test roadway supported by $\mathrm{D}$ section steel tube filled with concrete supports tended to be stable after a small movement. This test roadway can be used normally. Because of large deformation in roadway supported by 36 $\mathrm{U}$ section steel supports, data in this roadway have not been analyzed. Part of monitoring results is shown in Fig.
19.

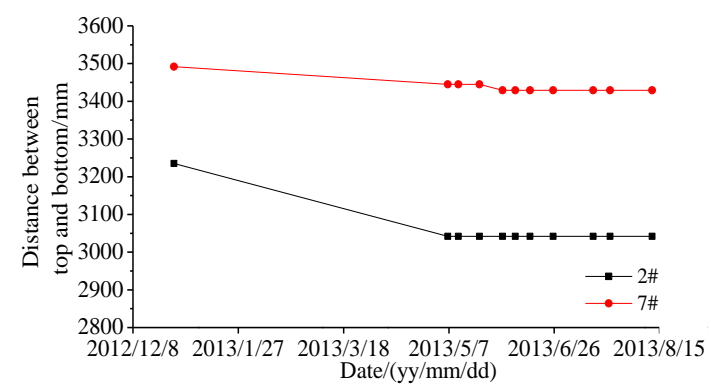

(a) Distance between top and bottom

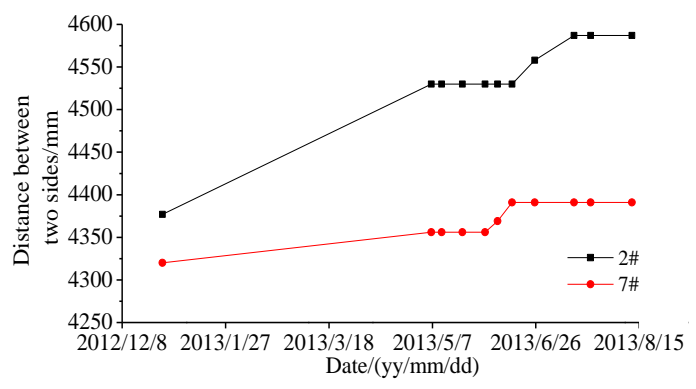

(b) Distance between two sides

Fig.19. Displacement of test roadway

Because there was a gap between supports and roadway wall at the beginning of supporting, supports did not play a role timely. Thus roof subsidence was obviously in the early stage of supporting. After a period of time, the surrounding rock and D section steel tube filled with concrete supports began to contact with each other. With the increasing of contact area, the deformation rate declined obviously, and the displacement of roadway tended to be stable. Because of the closed support is a whole support, roof subsidence caused outward expansion of two sides. Thus, in monitoring, two sides distance trended to increase. And in monitoring, supports damaged less and could ensure the normal use of this roadway. This verified that $D$ section steel tube filled with concrete supports are effective in deep mine roadway supporting.

\section{CONCLUSIONS}

In view of large deformation of roadway in deep mines, this paper puts forward a new support of D section steel tube filled with concrete. Based on compression simulation on circular ring, according to fractal geometry, the section of steel tube is designed as D section. By comparison, it is determined that the compressive strength of $\mathrm{D}$ section short steel tube filled with concrete is greater than that circular one and square one. When lateral pressure coefficient is 1.0 and 1.5 , the stress state in D section steel tube filled with concrete support is better than that of circular section support. By simulation and field application, it is verified that $\mathrm{D}$ section steel tube filled with concrete support is effective in deep mine roadway supporting.

\section{ACKNOWLEDGEMENT}

This study was supported by the National Natural Science Foundation of China [grant numbers [51604164] 
and by the program of youth teacher growth plan in Shandong province.

\section{REFERENCES}

[1] He Manchao, Qi Gan, Cheng Cheng, and et al., "Deformation and damage mechanisms and coupling support design in deep coal roadway with compound roof," Chinese Journal of Rock Mechanics and Engineering, vol. 26, no. 5, pp. 987-993, 2007.

[2] Sun Xiaoming, Wang Dong, Wang Cong, and et al., "Tensile properties and application of constant resistance and large deformation bolts," Chinese Journal of Rock Mechanics and Engineering, vol. 33, no. 9, pp. 1765-1771, 2014.

[3] Kang Hongpu, Wang Jinhua, and Lin Jian, "High pretensioned stress and intensive bolting system and its application in deep roadways," Journal of China Coal Society, vol. 32, no. 12, pp. 1233-1238, 2007.

[4] Zhang Nong, Hou Chaojiong, and Wang Peirong, "Research on bolt supporting technology in three soft coal roadway in deep well," Chinese Journal of Rock Mechanics and Engineering, vol. 18, no.4, pp. 437-440, 1999

[5] Gao Yanfa, Wang Bo, Wang Jun, and et al., "Test on structural property and application of concrete-filled steel tube support of deep mine and soft rock roadway," Chinese Journal of Rock Mechanics and Engineering, vol. 29, no. supp 1, pp. 2604-2609, 2010.

[6] Li Shucai, Shao Xing, Jiang Bei, and et al., "Study of the mechanical characteristics and influencing factors of concrete arch confined by square steel set in deep roadways," Journal of China University of Mining \& Technology, vol. 44, no. 3, pp. 400-408, 2015.

[7] Li Shucai, Wang Qi, Li Weiteng, and et al., "Comparative field test study of pressure relief anchor box beam support system in deep thick top coal roadway," Chinese Journal of Rock Mechanics and Engineering, vol. 31, no. 4, pp. 656-666, 2012.

[8] Xie Guangxiang, and Chang Jucai, "Study of space-time coupled and integrative supporting method of controlling the minimum deformation," Journal of China University of Mining \& Technology, vol. 42, no. 2, pp. 183-187, 2013.

[9] Wang Lianguo, Li Mingyuan, and Wang Xuezhi, "Study on mechanisms and technology for bolting and grouting in special soft rock roadways under high stress," Chinese Journal of Rock Mechanics and Engineering, vol. 24, no. 16, pp. 2889-2893, 2005.

[10] Xie Wenbing, Jing Shengguo, Wang Tao, and et al., "Structural stability of U-steel support and its control technology," Chinese Journal of Rock Mechanics and Engineering, vol. 29, no. supp 2, pp. 3243-3248, 2010.

[11] Wang Jinhua, "Study on deformation characteristics of rock surrounding coal roadways in coal mines with depth of $1000 \mathrm{~m}$ and strata control technology," Beijing: China University of Mining and Technology (Beijing), 2007

[12] Zhang Nong, WangCheng, Gao Mingshi, and et al., "Roadway support difficulty classification and controlling techniques for Huainan deep coal mining," Chinese Journal of Rock Mechanics and Engineering, vol. 8, no. 12, pp. 2421-2428, 2009

[13] Sun Xiaoming, Yang Jun, and Cao Wufu, "Research on space-time action rule of bolt-net-anchor coupling support for deep gateway," Chinese Journal of Rock Mechanics and Engineering, vol. 26, no. 5, pp. 895-900, 2007.

[14] Chang Jucai, and Xie Guangxiang, "Mechanical characteristics and stability control of rock roadway surrounding rock in deep mine," Journal of China Coal Society, vol. 34, no. 7, pp. 881-886, 2009.

[15] Zhou Ming, Gong Jianxiang, and Yan Lei, "High strength bolt support technique in deep well and soft-rock tunnel," China Mine Engineering, vol. 37, no. 4, pp. 31-33, 2008.

[16] Guo Jianwei, Liu Quansheng, Yang Zhanbiao, and et al., "Support technology to deep large-scale soft surrounding rock of roadway in Pingdingshan coal mine," Chinese Journal of Rock Mechanics and Engineering, vol. 31, no. supp 2, pp. 3904-3910, 2012.

[17] Yuan Liang, Xue Junhua, Liu Quansheng, and et al., "Surrounding rock stability control theory and support technique in deep rock roadway for coal mine," Journal of China Coal Society, vol. 36, no. 4, pp. 535-543, 2011

[18] Li Xuebin, Yang Renshu, Gao Yanfa, and et al., "High-strength steel tubular confined concrete supports support technology for large section soft rock inclined shaft," Journal of China Coal Society, vol. 38, no. 10, pp. 1742-1748, 2013

[19] Li Xuebin, Gao Yanfa, and Huang Wanpeng, "Analysis on surrounding rock stability of soft rock roadway supported by steel tube confined concrete supports during mine dynamic pressure," Science \& Technology Review, vol. 30, no. 16, pp. 42-47, 2012.

[20] Wang Bo, "Analysis on the laws of tunnel deformation in soft rock and the supporting technology of concrete-filled steel tube support," Beijing: China University of Mining and Technology (Beijing) 2009. 